\title{
Hospital Acquired Infections in a Selected Tertiary Level Hospital of Rangpur City
}

\begin{abstract}
MH Zaman', S Ferdouse ${ }^{2}$
Abstract

Objectives: To find out the proportion, to determine the average length of stay at hospital and to estimate the cost of treatment for hospital-acquired infections in a tertiary level hospital of Rangpur City.

Materials and Methods: This descriptive type of cross sectional study was conducted on purposively selected 200 admitted patients in a tertiary level hospital. Among them 100 were HAI patients and 100 were non HAI. Data were collected through duly pretested interviewer administered questionnaire and observation checklist.
\end{abstract}

Place and period of study: This study was conducted in Rangpur Medical College Hospital (RpMCH), Rangpur from January to June 2011.

Results: In this cross sectional study the highest percentage of HAI (42\%) belonged to the surgery ward and the lowest percentage (19.\%) belonged to medicine ward of the study hospital. According to the type of infections the surgical wound infection was found on the top (23\%) and the cannula-associated infection at the bottom (5\%) of the list. Respondents of both the polar age groups ( $<21$ years and $>60$ years) were found to be equally $(27 \%)$ affected by HAI. Occurrence of HAI was found higher (57\%) among the female respondents than their male (43\%) counterparts. Highest number (48\%) of HAI and lowest number (14\%) of non- HAI patients were found to be visited by maximum number $(\geq 5)$ of visitors. Among the respondents who developed HAI, 42\% had to stay at hospital for longest duration (21-25 days) but only 13\% of their non 7 HAI counterparts had to stay for same duration. Among HAI patients $26 \%$ had to spend highest amount of money (Tk.20,001/- 25,000/-) but among non- HAI patients only $10 \%$ had to spend same amount of money for their treatment purpose.

Conclusion: It has been revealed from this study that the occurrence of HAI was found higher among the patients with maximum number of visitors. Average length of hospital stay and cost of treatment of HAI patients were found higher than those of their non-HAI counterparts.

Key words: Hospital Acquired Infection (HAI), Cost of treatment, Average Length of Stay (ALS).

\section{Introduction}

A "hospital acquired infection (HAI)' - has been defined by WHO as: "an infection acquired in hospital by a patient who was admitted for a reason other than that infection," or as "an infection occurring in a patient in a hospital or other health care facility in whom the infection was not present or incubating at the time of admission. This includes infections acquired in the hospital but appearing after discharge, and also occupational infections among staff of the facility."1 The majority of HAI become evident 48 hours or more

1.Dr. Maruf Hasan Zaman BDS, MPH

Public Health Consultant

NIPSOM

2.Dr. Shahana Ferdouse BDS, MPH

Public Health Consultant

NIPSOM

\section{Address of Correspondence:}

Dr. Maruf Hasan Zaman BDS, MPH, Public Health

Consultant, NIPSOM,

E-mail-marufhzaman@yahoo.com following admission. In a study conducted by WHO in 55 hospitals of 14 countries representing 4 WHO regions (Europe, Eastern Mediterranean, South East Asia and Western Pacific) showed an average of $8.7 \%$ of hospital patients had nosocomial infections, the highest frequencies were reported from hospitals in the Eastern Mediterranean Region (11.8\%) followed by South East Asia where it was $10 \%$, with a prevalence of 7.7 and $9.0 \%$ respectively in the European and Western Pacific Regions. ${ }^{1,2}$ It has been revealed that at any time over 1.4 million people world-wide suffer from infectious complications.

Organism that further accentuates the problem. It has also been estimated that these infections cost more than US\$ 40 million every year in Thailand alone. ${ }^{3}$ In the prevalence studies on HAI conducted at Boston City hospital in 1964 and 1967, indicated that the prevalence was similar in both years and that surgical patients were more likely to be infected than were medical patients. ${ }^{4}$ A patient with a hospital infection might occupy a bed at least for three days longer than normal during which time nursing and medical staff might administer drugs and care for the patient. ${ }^{5}$ These 
costs could he financial, ouch as additional medications, travel costs or child care costs, or they could be non-financial, such as physical pain and emotional stress. Finally, if the infection delays patients or informal careers access to their usual activities, be they paid or un-paid, then productivity losses could accrue.

\section{Materisls and Methods}

This descriptive type of cross sectiongl study was contucted in a tertiary level hospital of Rangpur city. The study population comprised of 200 admitted patients, among them 100 were HAI patient and 100 were non HAI. as sample of this study. All the admitted patients found present during data collection period. Data were collected through duly pre tested interviewer administered questionnaire and observation checklist Only the Medicine, Surgery \& Gynecology wands were brought under study.

\section{Results}

Among 100 HAI patients' the highest percentage $42(42 \%)$ belonged to surgery wards, $38(38 \%)$ in Gyne 8. Obs. wards and only 19(19\%) belonged to medicine wards (Figure-1).

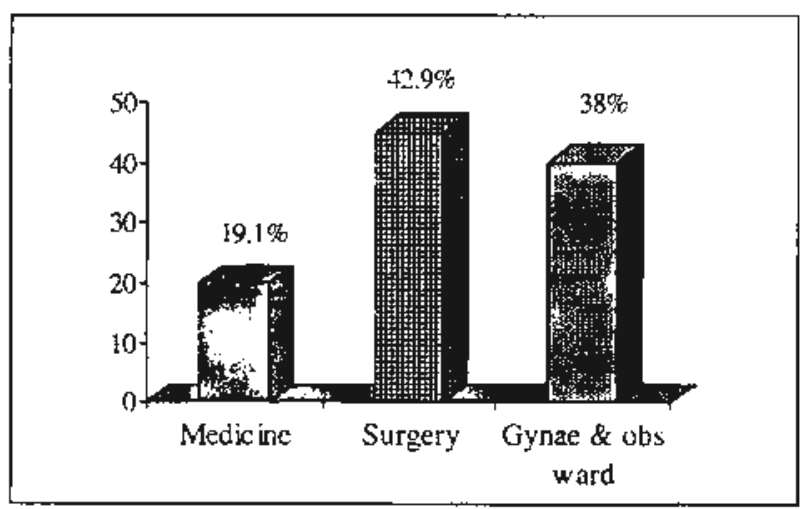

Figure 1: Distribution of the HAI patlents by treatment areas in the houpital

According to the type of infection Surgical Wound Infection (SWI) was found on the top (25\%) and Cannula-Associated Infection (CAD) was found at the bottom (6\%) of the list. The occurrence of Pelvic Inflammatory Disease (PID) and Skin Soft Tissue Infection (SSTI) were $20 \%$ and $16 \%$ respectively (Figure-2).

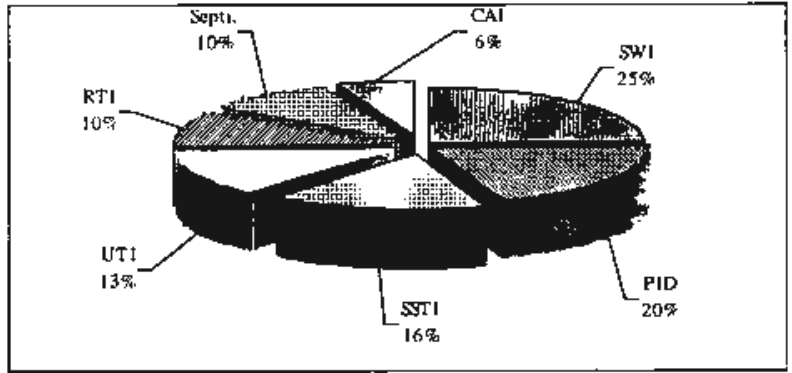

Figure 2: Distributlon of the respondents by type of HAI

Equal number (27\%) of HAI cases has been found among the (21-40 years) and extreme senior (61 years and above) age group. Near about the same percentage of respondents (26\%) was also belonged to extreme jumior (up to20 yearn) age group. Lowest number (20\%) of patients was found in age group of 41-60 years (Table 1)

Table 1: Distribution of the respondents by age and Types of HAI

\begin{tabular}{|c|c|c|c|c|c|}
\hline \multirow{3}{*}{ Tyव of } & \multicolumn{4}{|c|}{ 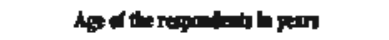 } & \multirow{3}{*}{ Tal } \\
\hline & Up by & $21-4$ & $41-\pi$ & ils & \\
\hline & Na $[\$$ & 1.h. (9) & Ko. (S) & 1.h. $(\$)$ & \\
\hline 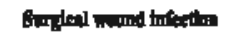 & $4(1750)$ & 460) & $4(179)$ & $9(\beta, 1)$ & IIIn) \\
\hline 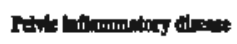 & 912080 & $5(\mathbf{n}, \mathrm{WJ})$ & $4(100)$ & (14) & II(14):0i) \\
\hline 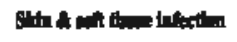 & 40697 & (933) & $4 \times \pi)$ & $2(1+0)$ & $15(10)$ \\
\hline 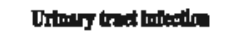 & 1ח,14) & $4(4,57)$ & 3(11.14) & $6(07.14)$ & 14(10) \\
\hline 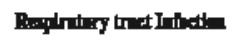 & $2(155)$ & $3(x, n)$ & 47m) & $425 \pi$ & L(10) \\
\hline 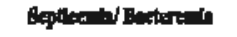 & 4(44) & $3(83 \pi)$ & 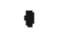 & $2(2 \pi)$ & xiton \\
\hline 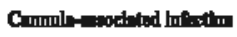 & $2(0)$ & 10 & 10 & 10. & (10) \\
\hline $\mathbf{T}$ & $x+0$ & $2 \pi(\pi)$ & 20(2) & $\pi(2)$ & $\ln (100)$ \\
\hline
\end{tabular}

Out of the $100 \mathrm{HAI}$ cases $57(57 \%)$ were female and only $43(43 \%)$ of them were male. Majority (58.3\%) of the respondents of surgical wound infection was male. All the $(100.0 \%)$ patients of Pelvic inflammatory disease were female. Majority of the respondents affected by Skin \& soft tissue infection (73.3\%) and Respiratory tract Infection (60\%) was male. Female majority cases were Urinary tract infection (75\%) and Septicemia / Bacteremia (45.5\%). Half (50.0\%) of the cannula $\neg$ associated infection was male and rest half was fernile. (Tuble-2) 
Table 2: Distribution of the respondents by sex and Types of HAI.

\begin{tabular}{|c|r|r|r|}
\hline \multirow{2}{*}{ Types of HAI } & \multicolumn{2}{|c|}{ Sex of the respondents } & \multirow{2}{*}{ Total } \\
\cline { 2 - 3 } & \multicolumn{1}{|c|}{ Male } & Female & \\
\hline Surgical wound infection & $14(58.33)$ & $10(41.67 \%)$ & $24(100.0 \%)$ \\
\hline Pelvic inflammatory dis. & 0 & $22(100.0 \%)$ & $22(100.0 \%)$ \\
\hline Skin \& soft tissue infection & $11(73.33 \%)$ & $4(26.67 \%)$ & $15(100.0 \%)$ \\
\hline Urinary tract infection & $3(25 \%)$ & $9(75 \%)$ & $12(100.0 \%)$ \\
\hline Respiratory tract Infection & $\mathbf{6 ( 6 0 \% )}$ & $4(40 \%)$ & $10(100.0 \%)$ \\
\hline Septicemia/ Bacteremin & $45(45.45 \%)$ & $6(54.54 \%)$ & $11(100.0 \%)$ \\
\hline Cannula-associated infection & $3(50.0 \%)$ & $3(50.0 \%)$ & $6(100.0 \%)$ \\
\hline Total & $43(43)$ & $57(57)$ & $100(100.0 \%)$ \\
\hline
\end{tabular}

It is evident from the following table that the occurrence of HAI was much more among the patients with greater number of visitors. Lowest percentage $(12 \%)$ of HAI and highest percentage $(44 \%)$ of nonHAI respondents were found visited by lowest number (0-1) of visitors. The number of visitors was 6 and more for $27(27 \%)$ HAI and $14(14 \%)$ non-HAI respondents (Table 3),

Table 3: Distribution of the respondents by Hospital Acquired Infections and number of Visitors

\begin{tabular}{|c|c|c|c|c|c|c|c|}
\hline \multirow{3}{*}{$\begin{array}{r}\begin{array}{r}\text { Type of } \\
\text { patients }\end{array} \\
\text { HAI }\end{array}$} & \multicolumn{5}{|c|}{ Number of Visitors } & \multirow{2}{*}{\multicolumn{2}{|c|}{ Total }} \\
\hline & \multirow{2}{*}{$\frac{0-1}{12(12)}$} & \multirow{2}{*}{\begin{tabular}{c|}
$2-3$ \\
$13(13)$
\end{tabular}} & \multirow{2}{*}{$\begin{array}{c}4-5 \\
48(48)\end{array}$} & \multicolumn{2}{|c|}{6 and $>$} & & \\
\hline & & & & 27 & (27) & 100 & (100.0) \\
\hline Non-HAI & $44 \quad(44)$ & $26(26)$ & $16(16)$ & 14 & (14) & 100 & (100.0) \\
\hline Total & $56(28.50 \%)$ & 39 (19) & 64 (32) & 41 & (21.50) & 200 & (100.0) \\
\hline
\end{tabular}

According to the following table it is evident that $6(6 \%)$ of the HAI and $50(50 \%)$ of the non- HAI respondents had to stay at hospital for shortest period (10 days and bellow). But 13(13\%) non-HAI patients and 42(42\%)HAI patient had to stay at hospital for longest period (more than 20 days)(Table- 4)

Table 4: Distribution of the respondents by Hospital Acquired Infections and length of hospital stay

\begin{tabular}{|c|c|r|r|r|c|}
\hline \multirow{2}{*}{$\begin{array}{c}\text { Types of } \\
\text { Datients }\end{array}$} & \multicolumn{3}{|c|}{ length of hospital stay (In days) } & \multirow{2}{*}{ Total } \\
\cline { 2 - 5 } & Up to 10 & $11-15$ & $16-20$ & $21-25$ & \\
\hline HAI & $6(6)$ & $11(11)$ & $41(41)$ & $42(42)$ & $100(100.0)$ \\
\hline Non-14AI & $50(50)$ & $25(25)$ & $12(12)$ & $13(13)$ & $100(100.0)$ \\
\hline Total & $56(23)$ & $36(18)$ & $53(26.50)$ & $55(27.50)$ & $200(100.0)$ \\
\hline
\end{tabular}

It is evident from the following table that $12(12 \%) \mathrm{HAI}$ and $24(24 \%)$ non-HAI patients had to spend lowest amount of money (up to Tk.5000/-) for their treatment. Nearly one third $26(26 \%)$ HAI and $10(10 \%)$ non-HAI patients had to spend highest amount of money (Tk.20,001-25,000/-) for the treatment purpose (Table 5).
Table 5: Distribution of the respondents by Category of diseases and amount of extra cost.

\begin{tabular}{|c|c|c|c|c|c|c|}
\hline \multirow[b]{2}{*}{$\begin{array}{l}\text { Type of } \\
\text { patients. }\end{array}$} & \multicolumn{5}{|c|}{ Amount of extra cost in Taka } & \multirow{2}{*}{ Total } \\
\hline & $\begin{array}{l}\text { Up to } \\
\text { TK, 50000- }\end{array}$ & $\begin{array}{c}\text { Tk, 5,000/- } \\
10,000 /-\end{array}$ & $\begin{array}{c}\text { Tk, 10,000/- } \\
15,000 /-\end{array}$ & $\begin{array}{c}\text { Tk,15,000/- } \\
\text { 20,004ty- }\end{array}$ & $\begin{array}{c}\text { Tk,20,000/- } \\
25,000 /-\end{array}$ & \\
\hline HAI & 12 (12) & $13(13)$ & 24 (24) & 25 (25) & $26(20)$ & $100(100.0 \%)$ \\
\hline Non-HAI & 24(24) & 38 (38) & $16(10)$ & 12 (12) & $10(10)$ & $100(100.0 \%)$ \\
\hline Total & $36(18)$ & $51(25.50)$ & 40 (20) & $37(18.50)$ & 36 (18) & $200(100.0 \%)$ \\
\hline
\end{tabular}

\section{Discussion}

In this cross sectional study in a tertiary level hospital of Rangpur City among 100 HAI patients 42(42\%) belonged to the surgery ward. The HAI patients belonged to gynae ward and medicine ward were $38(38 \%)$ and $19(19 \%)$ respectively. According to the type of HAI, surgical wound infection was found on the top (23\%) and cannula $\neg$ associated infection was found at the bottom (5\%) of the list. This distribution of HAI is consistent with the findings of the study conducted by Khan MH in $2003.7 \mathrm{He}$ also detected the surgical wound infection as the major cause of HAI, and Urinary Tract Infection as the second major cause. Regarding age distribution, though the difference was not statistically significant but respondents of two polar age groups were found more infected than their counterpart of middle age group. Hussain $\mathrm{T}$ et al in their study also found that age and sex distribution of HAI cases were not statistically significant, but the rate of HAI was more in the extremes of ages. It has been revealed from the study that the occurrence of HAI was much more among patients with greater number of visitors. The number of visitors was 6 and more for $27 \%$ HAI and $14 \%$ non-HAI respondents respectively. This study depicts that majority of the non-HAI patients were visited by minimum number $(0-1)$ of visitors per day. A similar finding was revealed in Tahmina's study ${ }^{9}$, she found that the prevalence of HAI was $37.5 \%$ among the patients who were visited by 9 visitors per day, whereas the prevalence was $21.8 \%$ among those patients who had least number of visitors (0-2) per day. ${ }^{6}$ This study revealed that patients with HAI had to stay for longer period in hospital than their nonHAI counterpart for treatment purpose. Hadi in his comparative study found that average length of hospital stay for HAI patients was 27.5 days. ${ }^{8}$ The shorter period of hospital stay found in this study indicate the improvement of hospital care at least to some extent. It has also been shown in the present study that the patients with HAI had to spend more money for their treatment than their non-HAI counterpart. Among all of them $26 \%$ HAI patients had to spend taka 20,000/- $-25000 /-$ but only $10 \%$ non-HAI patients had to spend that amount for treatment purpose. Khan (2000) found in his study that the majority $(38.29 \%)$ of the respondents spent TK $10000 /--20000 /-$ as extra cost for HAI. Mean extra cost was Tk. 20,435/- with SD $\pm 15,750.15^{7}$. 


\section{Conclusion}

Comparing the findings of the present study with that of the previous studies it is evident that the occurrence of the Hospital Acquired Infections is lower than that of the previous study. In spite of this attention should be given to operation theater and post operative zones, because surgical wound infection was still found on the top of the list among all HAI. Hospitals should also provide special care to the respondents of extreme junior and extreme senior age groups, because they were found to be more infected than their middle aged counterpart. This study depicts a high level of extra cost during the stay at hospital that could be averted by minimizing the occurrence of HAIs. Respondents with higher number of visitors were found to be affected more by HAI than their counterpart who had least number of visitors, so flow of visitors should be restricted for minimizing the prevalence of HAI.

\section{References}

1. WHO - Guidelines on prevention and Control of Hospital Associated Infections. Regional Office for SE Asia. New Delhi. January 2002: 1-3.

2. G. Ducel, et al. Prevention of HAI - A practical Guide, 2' ed. WHO; 2000: 1-7.
3. Wenzel RP. Prevention and Control of Nosocomial Infections. 3rd Ed. Williams \& Wilkins. Baltimore; 1997: 5-7.

4. Theodore C. Eickhoff. Airborne Nosocomial Infection: A Contemporary Perspective. JO Society for Health Care Epidemiology. Oct 1994; 15(10): 663-673.

5. Hall CB. Nosocomial viral respiratory infections: Perennial weeds in pediatric wards. In: Dixon RE, ed. Nosocomial Infections. York Medical Books; New York; 1981: 227-233.

6. Gulandaz HA. Pattern of Surgical Wound Infection in a Selected Tertiary Level Hospital. Dhaka; 1999-2000: 48.

7. Khan M.H. Hospital Acquired Infections: It's out come on Quality hospital care in a selected tertiary level Public Hospital. Dhaka; 2003: v-vi.

8. Hadi SA. A comparative Study on Factors Determining Post-operative Stay Due to Infection in a Selected Government Hospital and a Private Hospital. Dhaka; 1993: 37, 59, 68.

9. Hussain T, Fazal A, Ahmed A, Hussain A. Nosocomial Infection- A cross sectional study in the surgical ward of DMCH.JOPSOM 1999; 10(2):70-73. 